Чепухалина Е. В., Петренко И. А.

SММ КАК ПЕРСПЕКТИВНЫЙ СПОСОБ ПРОДВИЖЕНИЯ ТОВАРОВ И УСЛУГ

НА РОССИЙСКОМ РЫНКЕ

Чепухалина Е. В., Петренко И. А.

E. V. Chepukhalina, I. A. Petrenko

ЗММ КАК ПЕРСПЕКТИВНЫЙ СПОСОБ ПРОДВИЖЕНИЯ ТОВАРОВ И УСЛУГ НА РОССИЙСКОМ РЫНКЕ

\title{
SMM AS A PROMISING WAY TO PROMOTE GOODS AND SERVICES IN THE RUSSIAN MARKET
}

Чепухалина Елена Викторовна - кандидат экономических наук, доцент кафедры «Сервис и торговое дело» Комсомольского-на-Амуре государственного технического университета (Россия, Комсомольск-на-Амуре). E-mail: echepuhalina@mail.ru.

Ms. Elena V. Chepukhalina - $\mathrm{PhD}$ in economic sciences, associate professor, assistant professor of service and trade business department, Komsomolsk-on-Amur State Technical University (Russia, Komsomolsk-onAmur). E-mail: echepuhalina@mail.ru.

Петренко Иван Александрович - студент магистратуры 1 курса факультета экономики и менеджмента Комсомольского-на-Амуре государственного технического университета (Россия, Комсомольск-на-Амуре). E-mail: ride.1993@mail.ru.

Mr. Ivan A. Petrenko - Master's Degree Student of the first year major in Trade business, economics and management faculty, Komsomolsk-on-Amur State Technical University (Russia, Komsomolsk-on-Amur). E-mail: ride.1993@mail.ru.

Аннотация. В данной статье дано определение SMM (Social Media Marketing), классифицированы виды и инструменты социальных медиа, перечислены маркетинговые задачи, решаемые социальными медиа, а также проанализирована российская аудитория пользователей социальных медиа.

Summary. In this article definition to SMM is given (Social Media Marketing), types and tools of social media are classified, the marketing tasks solved by social media are listed, and the Russian audience of users of social media is analysed.

Ключевые слова: SMM, социальные медиа, виды социальных медиа, инструменты социальных медиа, маркетинговые задачи социальных медиа.

Key words: SMM, social media, types of social media, tools of social media, marketing tasks of social media.

УДК 339.138

В последние годы в маркетинговых коммуникациях произошли серьезные изменения, которые связаны с появлением новых каналов связи, таких как социальные медиа. Это послужило рождению нового направления коммуникаций - SMM (Social Media Marketing) продвижение товаров и услуг при помощи социальных медиа: социальных сетей, форумов, тематических площадок, блогосферы, профессиональных сообществ и других доступных на сегодняшний день социальных медиа-каналов. Сравнительно недавнее появление социальных медиа на российском рынке уже успело доказать эффективность данного маркетингового канала коммуникации, и, как следствие, стало необходимым и обязательным инструментом продвижения товаров и услуг для каждого участника интернет-рынка.

Возможности социальных медиа достаточно велики, объекты для продвижения с помощью данного канала разнообразны: это как товары и услуги, так и организации и их сайты. Задачи таких коммуникаций могут варьироваться от желания привлечь внимание к собственной деятельности и знакомства аудитории с брендом до рекламы конкретных товаров и услуг и увеличения посещаемости сайтов, что в конечном итоге направлено на достижение 
общей цели - росту конверсии. SMM обеспечивает возможность контактировать непосредственно с целевой аудиторией, выяснить ее конкретные потребности и получить обратный отклик. Посредством SMM можно привлечь на сайт поставщика новых потенциальных клиентов, которые активны в тематических сообществах. Социальные медиа-платформы имеют аудиторию, сопоставимую с аудиторией телевизионных каналов, но пользователи в интернете намного более активны и внимательны к новой информации. Наиболее эффективен SMM, осуществляемый в сообществах, где представлена целевая группа для продаваемых продуктов - прямое общение с заинтересованными людьми позволяет превратить их в будущих клиентов. А участие в профессиональных сообществах позволяет найти партнеров по бизнесу.

Различают следующие виды социальных медиа:

- по модели организации: социальные сети, форумы, тематические площадки, блоки и микроблоги, профессиональные сообщества и др. Социальная сеть представляет собой интернет-среду, где зарегистрированный пользователь может как разместить о себе информацию, так и коммуницировать с другими пользователями сети, устанавливая таким образом социальные связи («ВКонтакте», «Одноклассники»). Форум - интернет-площадка, где люди делятся своими мнениями и идеями, помогают друг другу советами, поддерживают в тяжелых жизненных ситуациях (komcity.ru.forum, maultalk.com). Тематические площадки - это чаще специализированные сайты, на которых собрана информация о том или ином рынке или направлении человеческой деятельности. На них можно найти статьи определенной тематики, блоги специалистов в определенной области, форумы по определенной теме и многое другое (kommersant.ru). Если же сайт в интернете создал и ведет эксперт, привлекающий внимание к различным аспектам своей деятельности и/или деятельности компании, в которой он работает - речь идет о блоге (Живой Журнал). Микроблог позволяет пользователям писать короткие заметки и публиковать их, а также любому желающему их прокомментировать («Twitter»). Профессиональные сообщества формируются как в рамках социальных сетей, так и специализированных, но общим у них является причина объединения - одна область профессиональной деятельности (linkedin.com);

- по направленности и/или функциональности - массовые и тематические. Массовые открыты для любого пользователя, подразумевают платформу для размещения почти любого контента, широкий охват аудитории. Массовые медиа могут включать в себя огромное количество как широконаправленных, так и узкоспециализированных тематических блоков и функций. Примерами таких медиа можно считать площадки для блогов, а также социальные сети вроде «ВКонтакте» или «Facebook». Тематические - обусловлены узконаправленной спецификой размещаемой информации и функций. Подобные площадки могут объединять в себя, скажем, специалистов в области it-технологий (habrahabr.ru), любителей музыки (last.fm), писателей (proza.ru), художников (deviantart.com) и так далее. А могут быть сформированы по форме размещаемой информации: фото- и видеохостинги, предназначенные для размещения видео («YouTube») или фото («Instagram»), или прямых трансляций («Twitch»), с возможностью оформления подписки и комментирования;

- по доступу - закрытые и открытые. Закрытость сообщества может быть вызвана спецификой обсуждаемых тем, но, не смотря на закрытость, такое сообщество может быть достаточно многочисленно. Получить доступ к такому сообществу часто трудно, еще труднее остаться членом этого сообщества, что требует особого подхода к инструментам воздействия на целевую аудиторию и объекту продвижения.

Социальные медиа позволяют не только продвигать свою продукцию или свое имя, но и дают возможность провести маркетинговые исследования по изучению настроения и потребностей покупателя, проследить их динамику, описать профиль потребителя, оценить его лояльность бренду. К маркетинговым задачам, которые можно решать при анализе данных социальных медиа, можно отнести: 
Чепухалина Е. В., Петренко И. А.

SММ КАК ПЕРСПЕКТИВНЫЙ СПОСОБ ПРОДВИЖЕНИЯ ТОВАРОВ И УСЛУГ

НА РОССИЙСКОМ РЫНКЕ

- изучение имиджа бренда в Интернете - имеется возможность видеть мнение людей, высказанное другим людям, а не исследователям и представителям компании;

- изучение влияния на имидж конкретных действий со стороны компании и отзывов людей;

- определение эмоциональной окраски сообщений, а через эмоциональную окраску психологические и психографические особенности пользователей;

- определение лояльности пользователей к бренду и др.

Появление или регистрация менеджера организации в социальных медиа - лишь первый шаг для достижения целей SMM. Важной составляющей работы такого специалиста является применение эффективного инструмента воздействия на целевого потребителя. Хорошо зарекомендовали себя следующие инструменты продвижения, используемые в SMM [1]:

- партизанская реклама - скрытая реклама, не воспринимаемая пользователем как реклама. Такой инструмент позволяет преодолеть недостаток классического рекламного воздействия, от которого пользователь старается закрыться или, в крайнем случае, просто не реагирует. Возможности интернет-технологий позволяют создать интересный видео-контент, который может не восприниматься как реклама, но достигать соответствующих целей;

- развлекательный характер контента - чтобы потребитель изучил информацию о товаре/услуге или организации, необходимо разместить интересный и познавательный контент, к которому можно отнести: статью эксперта, видеолекцию, лайфхак, подборку полезных ресурсов, инфографику, отзывы клиентов, презентации, тематический опрос и др.;

- вирусный маркетинг - добровольное распространение контента силами пользователей социальных медиа. Цель вирусного маркетинга в отличие от партизанского - не скрывать цель создания контента (реклама), а создать интересный рекламный ролик, который пользователь социальных медиа посоветует посмотреть другим;

- интерактивное общение - сама суть социальных медиа. Пользователь приходит в интернет-среду за общением, и реакция со стороны коммерческих организаций в форме совета или решения его проблемы воспринимается положительно. Можно создать аккаунт организации в социальных сетях для общения с пользователем, а можно участвовать в обсуждениях на специализированных площадках, например форумах.

Согласно исследованиям, проведенным компанией Brand Analytics в России в первом полугодии 2015 г. [2, 3], ежемесячно в социальных сетях появляется 620 млн сообщений от 35 млн авторов. В апреле 2015 года по активности пользователей на первом месте оказались социальные сети, затем идут: видеосервисы, блоги, форумы, сайты с отзывами, новости и комментарии к новостям. Согласно исследованию, «ВКонтакте» остается самым популярным социальным медиа с аудиторией в 53,6 млн человек (от 12 до 64 лет) в марте 2015 г. Следом идут «Одноклассники» - 38,75 млн человек, «Facebook» - 24,5 млн человек, «Мой мир» - 23,7 млн пользователей, «LiveJournal» - 16,4 млн человек. «Instagram» насчитывает 10,7 млн активных пользователей, а «Twitter» - 7,4 млн человек. Из всей аудитории в 53,6 млн человек «ВКонтакте» насчитывает 21,5 млн активных авторов (оставляют минимум одно публичное сообщение в месяц). Среди аудитории социальной сети больше женщин $58,1 \%$. Большинству пользователей «ВКонтакте» от 18 до 24 лет - 35,3\% всей аудитории. Активная аудитория составляет 14,8 \% от всего населения России. В «Одноклассниках» при аудитории в 38,75 млн человек 1,4 млн активных пользователей, что равно $0,95 \%$ всего населения страны. Женщины также лидируют - 69,2\%. Большинству пользователей от 25 до 34 лет - 23,8 \%. Почти столько же представителей возрастных групп 35-44 и более 55 лет 21,2 \% и 21,9 \% соответственно. В «Моем мире» 1,02 млн активных авторов. Вся ежемесячная аудитория социальной сети составила в марте 2015 года 23,7 млн человек. Большинству авторов от 35 до 44 лет. Женщин среди аудитории - 60,1\%. Общее число активных пользователей составляет 0,7 \% всего населения России. У «Facebook» 1,12 млн активных пользователей в России (0,77 \% населения страны) из 24,5 млн аудитории. 56,3 \% составляют женщины. 
В основной массе авторам от 25 до 34 лет - 37,2 \%. Из 10,7 млн пользователей «Instagram»2,4 млн являются активными. В гендерном распределении вновь лидируют женщины - 77,4 \%. Данные о возрасте авторов отсутствуют. Активные авторы составляют 1,63 \% от всего населения страны.

Данные исследования о профиле и объеме российской интернет-аудитории социальных медиа, многочисленные модели организации и инструменты социальных медиа позволяют коммерческим организациям достаточно эффективно как продвигать свой товар или организацию, так и добиваться решения маркетинговых задач по сохранению и преумножению своих пользователей, и, как следствие, покупателей.

\section{ЛИТЕРАТУРА}

1. Смирнова, М. В. SMM самостоятельно: как использовать социальные сети для продвижения бизнеса профессиональных услуг / М. В. Смирнова // Интернет-маркетинг. - 2015. - № 5. - С. 312-320.

2. Российская аудитория социальных сетей весной 2015 года // ADINDEX.RU: URL: http://adindex.ru/news/researches/2015/05/25/123830.phtml (дата обращения: 13.04.2016).

3. Савская, Т. П. Как использовать социальные сети для продвижения товара или услуги / Т. П. Савская // Интернет-маркетинг. - 2015. - № 4. - С. 230-242. 